\title{
Design of Microwave Antenna Array for Imaging of Multiphase Flows in Polypropylene Pipes
}

\author{
Khaldoun Alkhalifeh, Hatem Rmili (D), Bandar Hakim, Nebras Sobahi (D), \\ and Youssef AL-Turki \\ King Abdulaziz University, Electrical and Computer Engineering Department, P.O. Box 80204, Jeddah 21589, Saudi Arabia \\ Correspondence should be addressed to Hatem Rmili; hatem.rmili@yahoo.fr
}

Received 20 December 2020; Revised 22 April 2021; Accepted 11 May 2021; Published 24 May 2021

Academic Editor: Giuseppe Castaldi

Copyright ( $\odot 2021$ Khaldoun Alkhalifeh et al. This is an open access article distributed under the Creative Commons Attribution License, which permits unrestricted use, distribution, and reproduction in any medium, provided the original work is properly cited.

\begin{abstract}
The oil and gas industry requires accurate sensors to control fluid flow in pipelines during the production process from horizontal and near horizontal wells. The extracted crude oil is usually a multiphase mixture of oil, water, and gas, and the accurate measurement of the ratio of each multiphase within the pipeline is an important parameter to manage wells efficiently by maximizing the hydrocarbons that can be extracted. Various methods have been developed for determining the phase ratio including mechanical, optical, X-ray or gamma ray, ultrasound, nuclear magnetic resonance (NMR), and rarely microwave techniques. However, these methods do not permit the knowledge of the real-time evolution of the phase ratio and are less precise. Here, we propose and develop by simulation two microwave systems, in horizontal and vertical polarizations, to choose the optimal configuration for crude pipeline imaging applications. First, the pipeline containing crude oil was modeled and its thermal and dielectric properties are proposed. Then, the antennas array performances were optimized and assembled to the pipeline. Different numbers of antenna elements were successfully investigated using CST simulation in both vertical and horizontal polarizations to find the optimal number of antenna elements for the pipeline applications.
\end{abstract}

\section{Introduction}

Multiphase and three-phase flow (oil, water, and gas) are the main components while drilling oil. The exact proportion of multiphase flow components is a challenging problem to solve due to the differences in geological conditions, such as temperature, pressure, flow dynamics, and salinity. Some techniques based on gamma ray $[1,2]$ and X-ray [3] were used; however, these techniques require long measurement time and are based on ionizing radiations. The reduction of measurement time requires intense sources, which increases the cost and causes safety concerns [4]. In addition, the salinity variation of the water phase in the pipeline affects and introduces a significant source of error during the measurement procedure [5]. Another technique based on electrical impedance consists of measuring the impedance between two electrodes inserted in the oil-water-gas mixture flow.
However, the measured parameters (resistance and capacitance) depend highly on the dielectric properties (permittivity and conductivity) of the three phases (oil, water, and gas), their fractions, the flow regime, and the operating frequency [6]. This high dependence on many parameters leads to large errors in measurements. Ultrasound Doppler velocimetry was employed to measure the liquid velocity, where the velocity is used to realize real-time flow regime identification with the help of machine learning [7]. Recently, the use of microwave attenuation and phase shift appeared as an emerging technique used to overcome some deficiencies related to the previous techniques. To overcome the problem of high sensitivity of measurement, the pulsed neutron activation (PNA) technique was proposed. This technique uses a high-energy source of neutrons to irradiate the flowing mixture. The emitted gamma radiation is used to determine the chemical composition and phase fractions of the mixture, but this technique is expensive and uses 
ionizing radiation. Another technique was developed and utilized, the nuclear magnetic resonance (NMR), by applying a magnetic field to the flow of the mixture to align spin states of the nuclei [8]. The spin realignment may be related to the chemical composition and hence the phase fractions of the flow. Again, this technique is heavy and expensive. The microwave technique was performed by measuring the permittivity and conductivity of the flowing mixture at different microwave frequencies by determining both the amplitude and phase of transmission coefficients to the electromagnetic waves that passed through the flow [9], or by determining the frequency shift of a resonating cavity carrying the fluid flow [10]. However, the resonant technique suffers from two main limitations: single frequency measurement and the presence of water which may introduce a high perturbation of electromagnetic fields in the cavity due to its conducting behavior [11]. However, although microwave methods require more complex excitation and detection circuitry than impedance methods, they have been successfully utilized in a number of three-phase flow meters [11].

The main applications of UWB antennas array are medical imaging [12-14], through-wall imaging [15], ground penetration radar (GPR) [16], and indoor geolocation and positioning [17]. Tapered slot antennas are widely known either by elliptical proles [18] or exponential profiles [19]. 3$D$ circular connected Vivaldi elements are proposed in [20], where they used an array of 10 elements with an elliptical taper profile for near-field radar imaging applications. Antenna array with 16 elements is proposed to achieve an omnidirectional UWB horizontal polarization antenna [21]. In this work, we propose and develop by simulation a new 3$D$ microwave imaging system based on circular array antennas to determine the real-time phase ratio of crude oil within the pipeline. The array antennas will scan one cylindrical section of the pipeline and produce 2-D images, in which it will quantify the localization of the oil in the pipeline and its ratio. Thus, better real-time monitoring of the well production could be successfully realized. The proposed antennas array consists of a circular ring of 32 UWB Vivaldi antennas operating over a band of $1 \mathrm{GHz}$ to more than $7 \mathrm{GHz}$. The array will be a part of a complete microwave system based mainly on a 16/32 MIMO system based on software defined radio (SDR) technology or 8-port vector network analyzer with a switching network and software for analysis of all signals and generation of the scanned images.

\section{Pipeline Model Assumption}

The pipeline is represented by its main three components of oil, water, and gas and a combination of a cylinder of water in blue color $(6 \mathrm{~cm}$ diameter, $10 \mathrm{~cm}$ height $)$ and a cylinder of oil in black color $(6 \mathrm{~cm}$ diameter, $10 \mathrm{~cm}$ height). Both cylinders are surrounded by air (gas representation). The pipeline tube material is defined as polyether ether ketone (PEEK) which is a technical plastic. The outer diameter of PEEK tube is set to $20 \mathrm{~cm}$, with $0.3 \mathrm{~cm}$ thickness and $10 \mathrm{~cm}$ height. Table 1 summarizes the thermal and electromagnetic properties used in the CST thermal transient solver for water, oil [22], and PEEK (polymide) materials (Figure 1).

2.1. Design of a 3-D Single Vivaldi Element. The unit element for the microwave imaging system is shown with its parameters in Figure 2, where A is the antenna length, $\mathrm{B}$ is the antenna width, $\mathrm{R}$ is the cavity diameter, $\mathrm{Lg}$ is the distance between the ground plan and the bottom of the circular cavity, and $\mathrm{C}$ is the aperture width. The single element is designed using CST (computer simulation technology, $\mathrm{GmbH}$ ) microwave studio simulation tools [22]. Time-domain solver will be used to simulate the different structures. A ground plan of $0.5 \mathrm{~cm}$ thickness is added to hold the antenna properly. The antenna material is set to aluminum. The type of taper profile is exponential.

2.2. Design of the Microwave System. In this section, we will present the advantages of the horizontal and vertical Vivaldi antennas and then choose the best configuration in terms of antenna bandwidth, $\mathrm{S}_{21 \mathrm{~A}}$ average (add up all transmission coefficients of $S_{21}$ values divided by how many $S_{21}$ numbers), miniaturization, and number of elements. From the antenna point of view, lower $S_{21}$ leads to less mutual coupling between antennas, which has less impact on the embedded radiation patterns and input impedance [23].

2.2.1. Design of a 3-D Circular Array in Horizontal Polarization. 3-D circular arrays of three different configurations with 8,16 , and 32 Vivaldi elements in horizontal polarization (HP) are proposed, developed, and simulated, as shown in Figure 3. The single element parameters are reported in Table 2 for each configuration.

The 32-element case shown in Figure 3(c) was performed by fixing the dimensions of the single element of 16-element case, producing 32 array dimensions with $89.6 \times 89.6 \mathrm{~cm}^{2}$.

However, the simulation time will be increasing dramatically. Optimizing such a large array is difficult to achieve by CST time-domain solver due to the huge number of mesh cells to solve. Some numerical methods could be applied to reduce the simulation time such as array scanning method (ASM) [24]. Figure 4(a) shows the array bandwidth of 8element array between $1.47 \mathrm{GHz}$ up to more than $7 \mathrm{GHz}$. The distance between antennas and PEKK is $3.1 \mathrm{~cm}$. Since there is enough space between the array elements, the mutual coupling is relatively low. The $S_{21 A}$ average gives $-21.5 \mathrm{~dB}$. Figures 4(b) and 4(c) present the antenna array performance of 16-element case, and it shows a bandwidth from $1.45 \mathrm{GHz}$ to more than $7 \mathrm{GHz}$ below $-10 \mathrm{~dB}$ criterion. The transmission coefficient average $S_{21 A}$ of 16 elements is higher than 8 elements due to the shorter distance between the radiating elements. $S_{21 A}$ average value gives $-16.7 \mathrm{~dB}$.

\subsubsection{Design of a 3-D Circular Array in Vertical Polarization.} The main advantage of vertical element configuration is the possibility of arranging higher number of elements in an array compared with the horizontal configuration. Three different configurations with 8,16 , and 32 Vivaldi elements 
TABLe 1: Electromagnetic and thermal parameters at $2.45 \mathrm{GHz}$.

\begin{tabular}{lcccc}
\hline & Oil & Water & PEEK & Unit \\
\hline Real part of permittivity & 2.33 & 78 & 3.1 & - \\
Dielectric loss factor & 0.001 & 16 & 0.003 & 0.20 \\
Thermal conductivity & 0.25 & 0.5986 & 0 & $\mathrm{~W} / \mathrm{m} / \mathrm{K}$ \\
Convection coefficient & 300 & 0 & $\mathrm{~W} / \mathrm{m}^{2} / \mathrm{K}$ \\
Density & 820 & 998.6 & 1400.0 & 1 \\
Heat capacity & 2.732 & 4.1842 & $\mathrm{~kg} / \mathrm{m}^{3}$ \\
Temperature & 25 & 25 & $\mathrm{~kJ} / \mathrm{K} / \mathrm{kg}$ \\
\hline
\end{tabular}

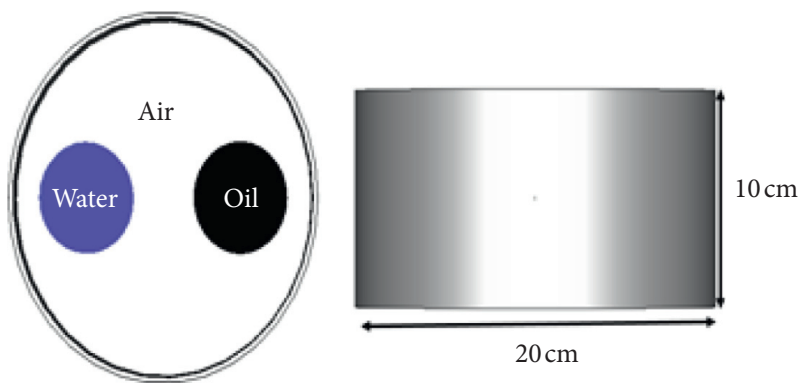

FIGURE 1: Pipeline model layout with its three main components of water, oil, and air.

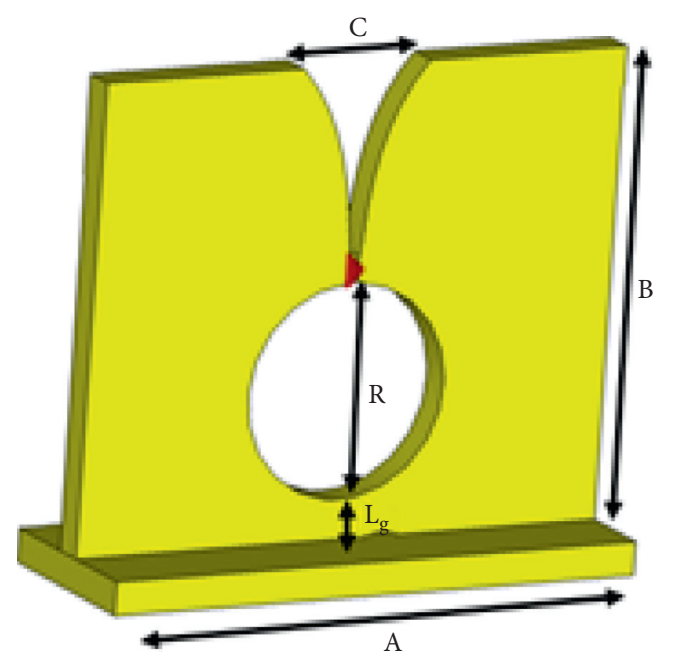

Figure 2: Single element parameters definition.

in vertical polarization (VP) are proposed, as shown in Figure 5. The single element parameters are reported in Table 3 for each configuration.

The proposed large antenna array design of 32 elements is shown in Figure 5(c). The 32 array dimension is $68.3 \times 68.3 \mathrm{~cm}^{2}$, which is less than the horizontal design by $24 \%$.

Figure 6(a) shows the array bandwidth of 8-element array between $1.28 \mathrm{GHz}$ up to more than $7 \mathrm{GHz}$. The distance between antennas and PEKK is $7 \mathrm{~cm}$. The space between the array elements is $16 \mathrm{~cm}$, which produces $S_{21 A}$ average of $-23.15 \mathrm{~dB}$. As presented in Figures 6(b) and 6(c), the antenna array performance in terms of reflection and transmission coefficients shows less than $-10 \mathrm{~dB}$ for a bandwidth range from $1.17 \mathrm{GHz}$ to more than $7 \mathrm{GHz}$. The
$\mathrm{S}_{21 A}$ average of 16 elements is slightly higher than 8 elements due to the shorter distance between the radiating elements. $\mathrm{S}_{21 \mathrm{~A}}$ average value records $-21.19 \mathrm{~dB}$. The antenna bandwidth starts from $1.17 \mathrm{GHz}$ up to more than $7 \mathrm{GHz}$. The distance between antennas and PEKK is $13.1 \mathrm{~cm} . \mathrm{S}_{21 \mathrm{~A}}$ average value records $-18.6 \mathrm{~dB}$. Table 4 summarizes the performance of horizontal and vertical polarizations. For 8element configuration case, both designs are similar in terms of array dimensions and the lower cut-off frequencies. However, the vertical polarization design exhibits lower $S_{21 A}$ value. Also, it is noticed that the VP array configuration has lower $\mathrm{S}_{21 A}$ than HP ones for 16-element case. The optimized 32-element array design has a satisfactory result in terms of antenna bandwidth, array size, and system complexity.

\section{Thermal Analysis}

The following is a study of the temperature variation over the entire structure based on thermal losses in the conductors and dielectric materials. These thermal losses are computed using the frequency electromagnetic solver at $2.45 \mathrm{GHz}$.

3.1. The Electromagnetic Thermal Model. Simulating the heating process of pipelines is technically challenging to be achieved since there is no report so far that has been studied their thermal properties, especially the PEEK. The complexity of finding the pipeline heating transfer coefficients is due to nonlinear functions of thermal model parameters that relay on temperature and water content. Therefore, the following case study will consider tabulated data as well as the default properties mentioned above. According to the technical data sheet [25], each element can handle an input power level of $350 \mathrm{~W}$, in which it will produce $5.6 \mathrm{~kW}$ as nominal power. The exposure duration and ambient temperature are set to 450 seconds and $25^{\circ} \mathrm{C}$, respectively.

The maximum temperature distribution is rescaled to $50^{\circ} \mathrm{C}$ to detect the water component inside the pipeline, as shown in Figure $7(\mathrm{a})$, and rescaled to $29^{\circ} \mathrm{C}$ to distinguish between the oil component and ambient temperature. Therefore, the water is clearly detected among the oil and air inside the pipeline due to its large dielectric constant compared to oil. Also, the close section of PEEK tube is affected by water heating. The oil model is mostly heated at $26.5^{\circ} \mathrm{C}$, whereas the section close to water is heated to $29^{\circ} \mathrm{C}$. It is noticed that the central section of oil is heated more than $26.5^{\circ} \mathrm{C}$ due to focus radiated power at the pipeline center. As the oil real part of permittivity is close to air value, it is challenging to distinguish between both materials by their response to microwave heating. 


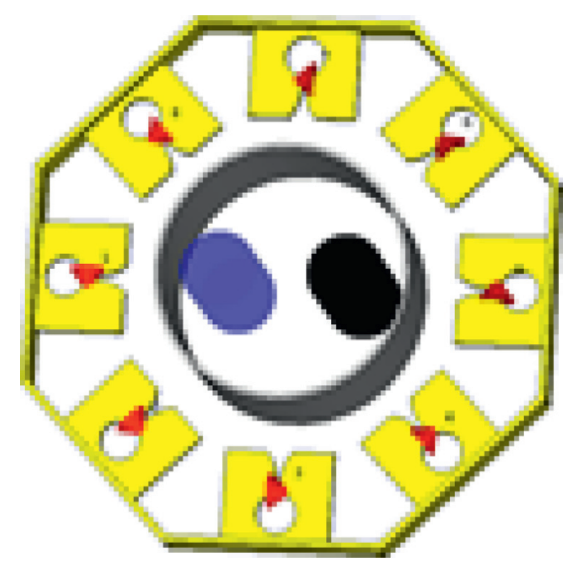

(a)

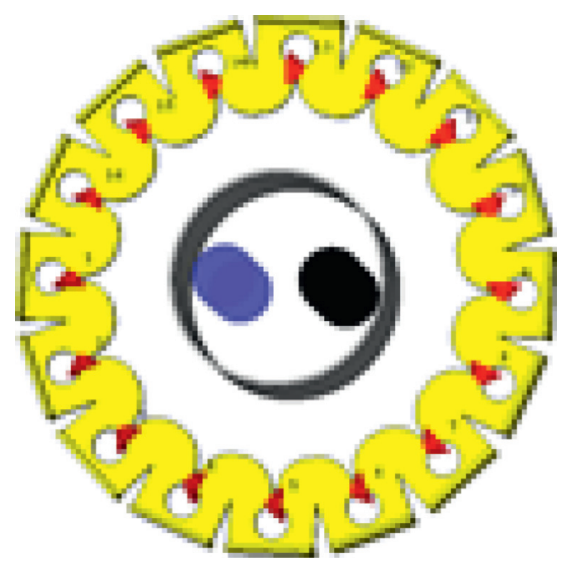

(b)

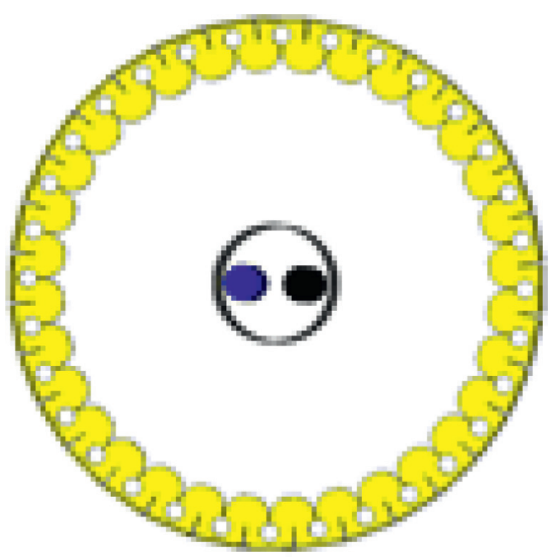

(c)

Figure 3: Microwave system of antenna arrays in horizontal polarization for (a) 8 elements, (b) 16 elements, and (c) 32 elements.

TABLe 2: Single element parameters (horizontal polarization).

\begin{tabular}{lccccc}
\hline- & $\mathrm{A}$ & $\mathrm{B}$ & $\mathrm{C}$ & $\mathrm{R}$ & $\mathrm{L}$ \\
\hline 8 elements & 8.5 & 7.0 & 2.0 & 5.4 & 4 \\
16 elements & 8.92 & 8.0 & 5.1 & 4.5 & 0.6 \\
32 elements & 8.92 & 8.0 & 0.6 \\
\hline
\end{tabular}

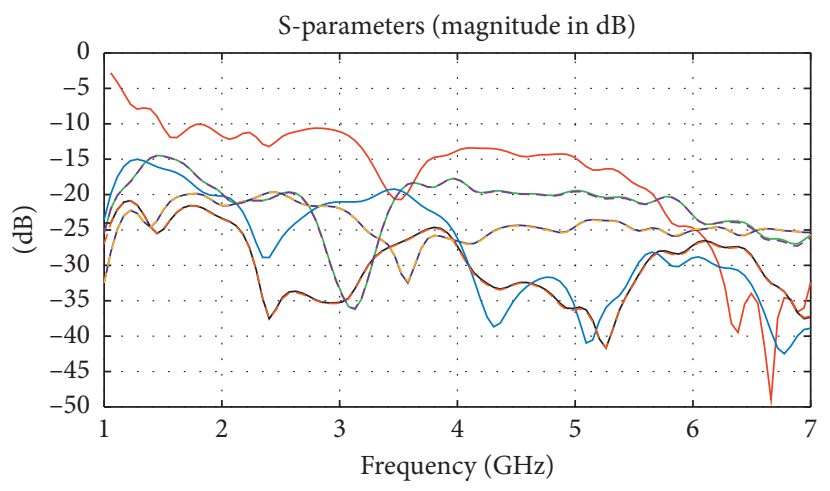

$\begin{array}{rr}-\mathrm{S} 1,1 & -\mathrm{S} 5,1 \\ -\mathrm{S} 2,1 & --\mathrm{S} 6,1 \\ -\mathrm{S} 3,1 & --\mathrm{S} 7,1 \\ -\mathrm{S} 4,1 & --\mathrm{S} 8,1\end{array}$

(a)

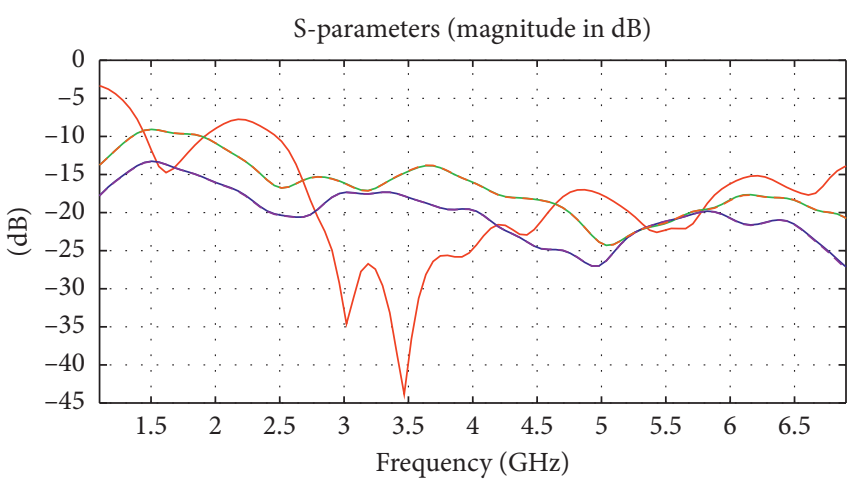

$\mathrm{S} 1,1$
$-\mathrm{S} 2,1$
$\mathrm{~S} 3,1$

- - S S15, 1

- - S16, 1

Figure 4: Continued. 


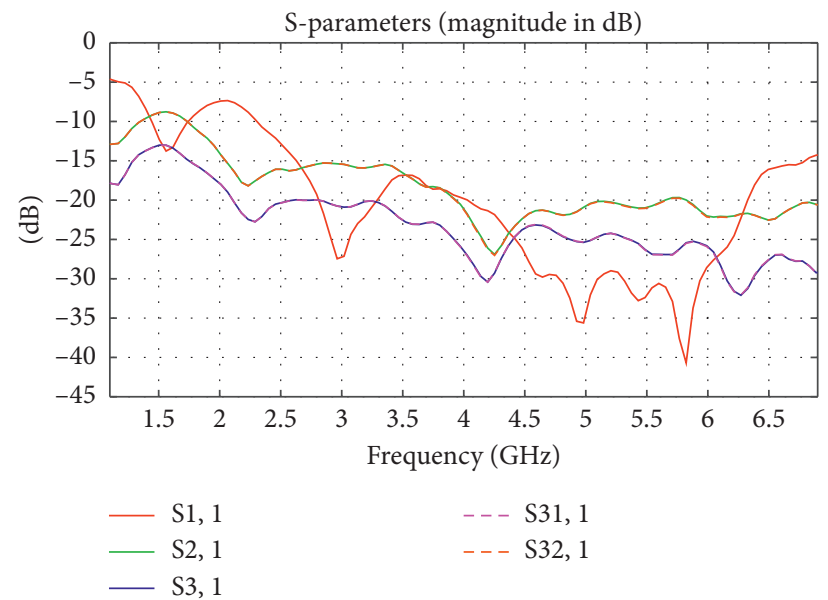

(c)

Figure 4: The horizontal scattering matrix of (a) 8 elements, (b) 16 elements: S1,1-S2,1-S3,1-S15,1-S16,1, and (c) 32 elements: S1,1-S2,1S3,1-S31,1-S32,1.

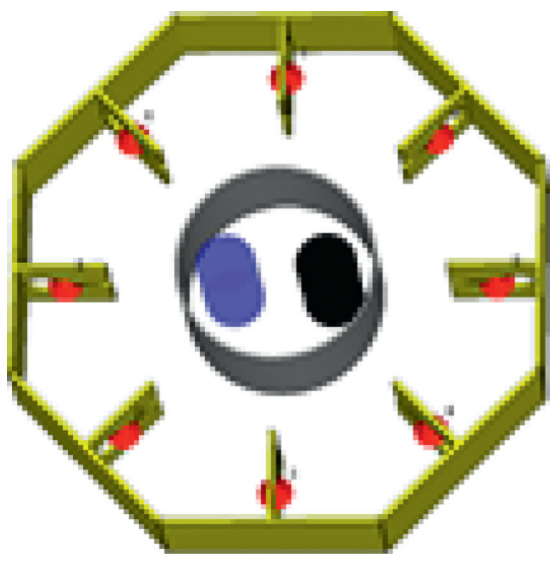

(a)

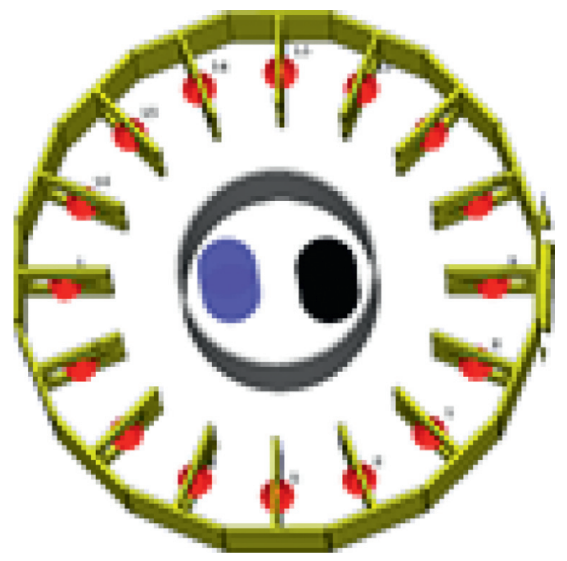

(b)

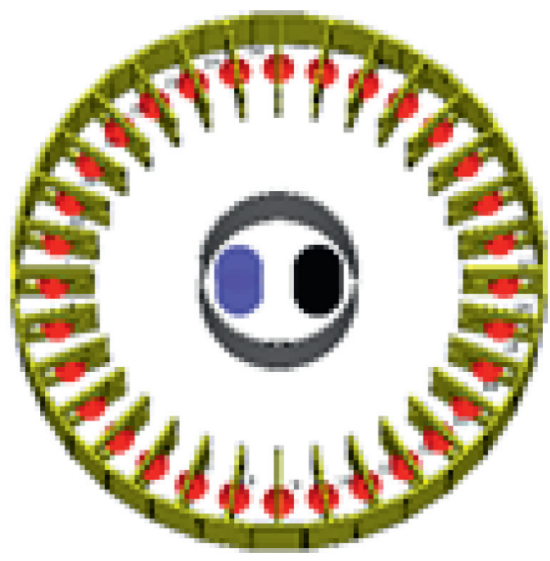

(c)

Figure 5: Microwave system of antenna arrays in vertical polarization for (a) 8 elements, (b) 16 elements, and (c) 32 elements.

TABLE 3: Single element parameters (vertical polarization).

\begin{tabular}{lcccrr}
\hline- & $\mathrm{A}$ & $\mathrm{B}$ & $\mathrm{C}$ & $\mathrm{R}$ & \\
\hline 8 elements & 9 & 8.9 & 1.5 & 3.8 & \\
16 elements & 9.4 & 9.0 & 1.5 & 4.6 & 0.3 \\
32 elements & 11.0 & 9.0 & 3.6 & 4.6 & 0.5 \\
\hline
\end{tabular}



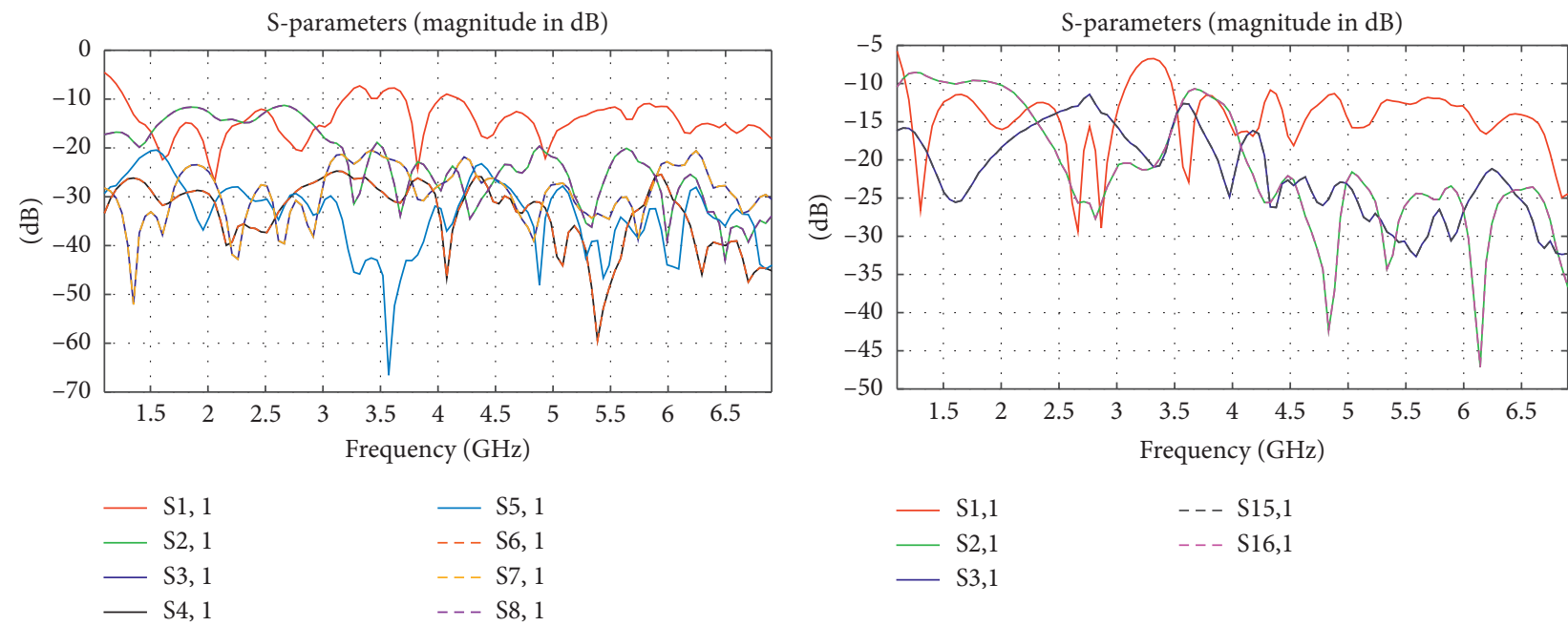

$$
\begin{aligned}
& \text { S } 5,1 \\
& - \text { - - S } 6,1 \\
& -- \text { S } 7,1 \\
& - \text { - S S , 1 }
\end{aligned}
$$$$
-\mathrm{S} 1,1+-\mathrm{S} 15,1
$$$$
\text { - S2,1 }
$$$$
\text { - - S16,1 }
$$

(a)

(b)

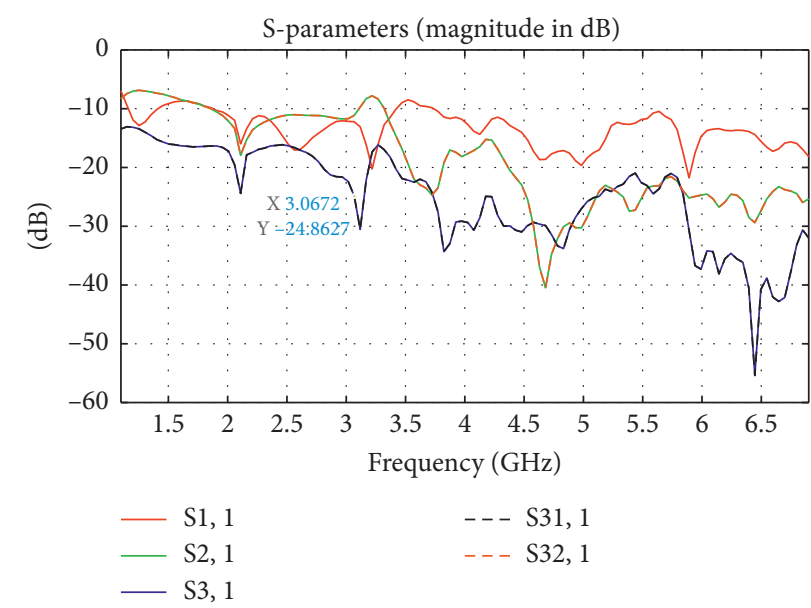

(c)

Figure 6: The vertical scattering matrix of (a) 8 elements, (b) 16 elements: S1, 1-S2, 1-S3, 1-S15, 1-S16, 1, and (c) 32 elements: S1, 1-S2, 1-S3, $1-\mathrm{S} 31,1-\mathrm{S} 32,1$.

TABLE 4: Main performances of both horizontal and vertical polarization arrays.

\begin{tabular}{lccc}
\hline- & HP-8 & HP-16 & HP-32 \\
\hline $\mathrm{S}_{21 A}(\mathrm{~dB})$ & -21.5 & -16.7 & - \\
Cut-off frequency $(\mathrm{GHz})$ & 1.47 & 1.45 & - \\
Dimensions $\left(\mathrm{cm}^{2}\right)$ & $41.4 \times 41.4$ & $49.9 \times 49.9$ & $89.6 \times 89.6$ \\
- & $\mathrm{VP}-8$ & $\mathrm{VP}-16$ & $\mathrm{VP}-32$ \\
$\mathrm{~S}_{21 A}(\mathrm{~dB})$ & -23.15 & -21.19 & -18.6 \\
Cut-off frequency $(\mathrm{GHz})$ & 1.28 & 1.17 & 1.16 \\
Dimensions $\left(\mathrm{cm}^{2}\right)$ & $52.7 \times 52.7$ & $52.7 \times 52.7$ & $68.3 \times 68.3$ \\
\hline
\end{tabular}




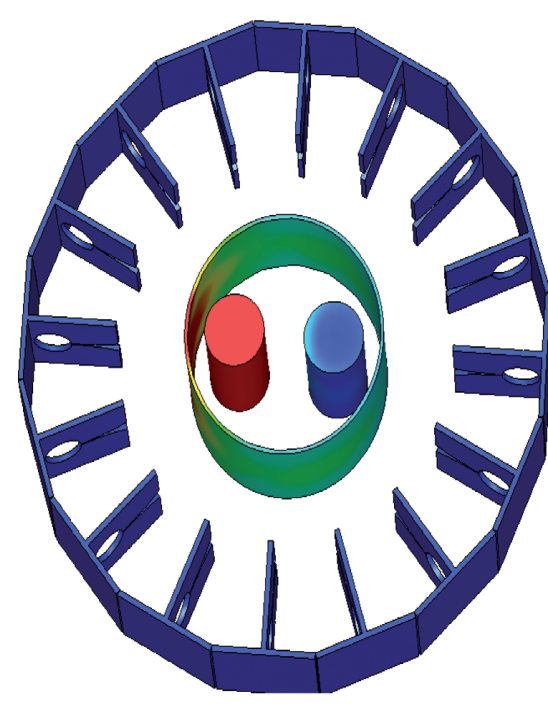

(a)
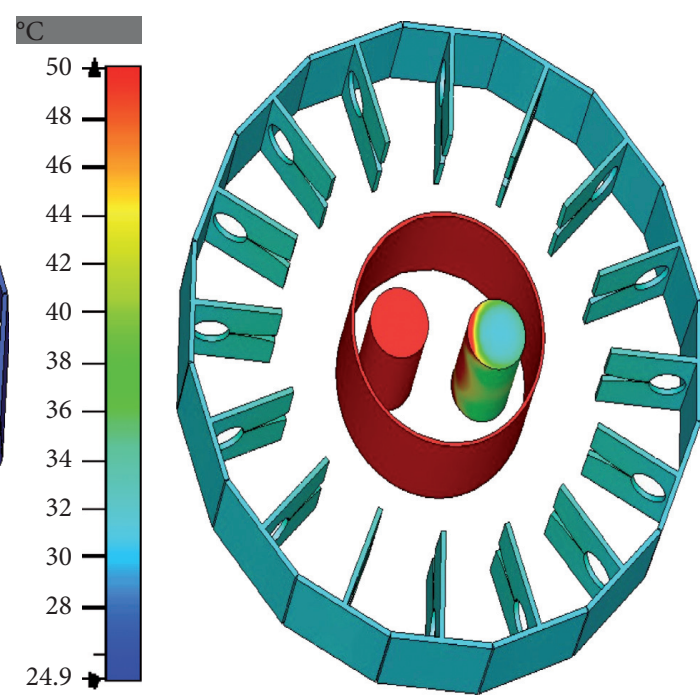

(b)

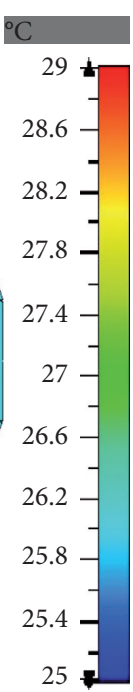

Figure 7: Temperature distribution with (a) $50^{\circ} \mathrm{C}$ and (b) $29^{\circ} \mathrm{C}$ maximum representation.

\section{Conclusion}

The antenna vertical polarization is advantageous over the horizontal polarization due to the relatively small size in the case of using large number of antenna elements. The large number of antenna elements has major advantages of providing more information about the pipeline components, which is an essential element for accurate pipeline image reconstruction algorithms. For 8- and 16-element array configurations, VP array shows lower $S_{21 A}$ values, which express lower mutual coupling. Both HP and VP arrays show similar proportion for their dimensions and lower cut-off frequencies. For 32-element case, VP is preferable over the HP configuration due to its compact size and acceptable $S_{21 A}$ value. The thermal analysis presents the pipeline components at different temperatures, where the water can be seen at $50^{\circ} \mathrm{C}$, oil at $26.5^{\circ} \mathrm{C}$, and gas at ambient temperature of $25^{\circ} \mathrm{C}$.

\section{Data Availability}

The results of this study are available from the corresponding author.

\section{Conflicts of Interest}

The authors declare that they have no conflicts of interest.

\section{Acknowledgments}

This project was funded by the Science and Technology Unit, King Abdulaziz University, Kingdom of Saudi Arabia, award number (UE-41-103).

\section{References}

[1] M. Roshani, G. T. T. Phan, P. Jammal Muhammad Ali et al., "Evaluation of flow pattern recognition and void fraction measurement in two phase flow independent of oil pipeline's scale layer thickness," Alexandria Engineering Journal, vol. 60, no. 1, pp. 1955-1966, 2021.

[2] M. Roshani, "Proposing a gamma radiation based intelligent system for simultaneous analyzing and detecting type and amount of petroleum by-products," Nuclear Engineering and Technology, vol. 53, pp. 1277-1283, 2020.

[3] M. Roshani, G. Phan, G. H. Roshani et al., "Combination of $\mathrm{X}$-ray tube and GMDH neural network as a nondestructive and potential technique for measuring characteristics of gasoil-water three phase flows," Measurement, vol. 168, Article ID 108427, 2021.

[4] H. Van Santen, Z. I. Kolar, and A. M. Scheers, "Photon energy selection for dual energy -and/or X-ray absorption composition measurements in oilwatergas mixtures," Nucl. Geophysics.vol. 9, pp. 193-202, 1995.

[5] A. M. Scheers and W. Letton, "An Oil/water/gas composition meter based on multiple energy gamma ray absorption," in Proceedings of the (MEGRA) Measurement Proc. 14th North Sea Flow Measurement Workshop, Bergen, Norway, October 1996.

[6] Z. Almutairi, F. M. Al-Alweet, Y. A. Alghamdi, O. A. Almisned, and O. Y. Alothman, "Investigating the characteristics of two-phase flow using electrical capacitance tomography (ECT) for three pipe orientations," Processes, vol. 8, 2020.

[7] Y. Zhang, A. N. Azman, K. W. Xu, C. Kang, and H. B. Kim, "Two-phase flow regime identification based on the liquidphase velocity information and machine learning," Experiments in Fluids, vol. 61, pp. 1-16, 2020.

[8] G. J. Krüger, A. Birke, and R. Weiss, "Nuclear magnetic resonance (NMR) two-phase mass flow measurements," Flow Measurement and Instrumentation, vol. 7, no. 1, pp. 25-37, 1996.

[9] S. L. Ashton, N. G. Cutmore, G. L. Roach, J. S. Watt, H. W. Zastawny, and A. J. McEwan, "Development and trial of microwave techniques for measurement of multiphase flow of oil, water and gas," in Proceedings of the SPE Asia Pacific Oil and Gas Conference, Society of Petroleum Engineers, Melbourne, Australia, November 1994. 
[10] S. Gainsford and H. O. Hide, "Field testing of the multi-fluid LP multiphase meter," in Proceedings of the 11th North Sea Flow Measurement Workshop, Bergen, Norway, October 1993.

[11] B. Hogan, A. I. Al-Shamma'a, and J. Lucas, "Real-time multiphase metering using nonIntrusive microwave sensor," in Proceedings of the 2nd North American Conference on Multiphase Technology, pp. 281-296, Banff, Canada, June 2000.

[12] E. L. Larsen and J. H. Jacobi, Medical Applications of Microwave Imaging, IEEE Press, The institute of Electrical and Electronic Engineers, Inc., New York, NY, USA, 1985.

[13] S. Y. Semenov, R. H. Svenson, A. E. Boulyshev et al., "Microwave tomography: two-dimensional system for biological imaging," IEEE Transactions on Biomedical Engineering, vol. 43, no. 9, pp. 869-877, 1996.

[14] E. C. Fear, S. C. Hagness, P. M. Meaney, M. Okoniewski, and M. A. Stuchly, "Enhancing breast tumor detection with nearfield imaging," IEEE Microwave Magazine, vol. 3, no. 1, pp. $48-56,2002$.

[15] O. O. Drobakhin, M. O. Drobakhina, V. K. Korotkaya, and G. G. Sherstyuk, "Recognition of Microwave Multifrequency Images of Objects Hidden behind Wall," in Proceedings of the 2012 6th International Conference on Ultrawideband and Ultrashort Impulse Signals, pp. 120-122, Sevastopol, Ukraine, 2012.

[16] J. J. Daniels, Ground Penetrating Radar, Institute of Electrical and Electronics Engineers, Piscataway, New Jersey, USA, 2004.

[17] J. D. Taylor, Ultra-WidebandRadar Technology, CRC Press, Boca Raton, Florida, USA, 2001.

[18] R. Sarkis and C. Craeye, "Circular Array of Wideband 3D Vivaldi Antennas," in Proceedings of the Electromagnetic Theory (EMTS), on URSI International Symposium, pp. 792794, Berlin, Germany, August 2010.

[19] M. Amiri, F. Togh, A. Ghafoorzadeh-Yazdi, and M. Abolhasan, "Exponential antipodal Vivaldi antenna with exponential dielectric lens," IEEE Antennas and Wireless Propagation Letters, vol. 1, pp. 1792-1795, 2017.

[20] K. Alkhalifeh, A. Cosse, C. Craeye, and B. Macq, "Microwave imaging from wheel-of-time data," in Proceedings of the 8th European Conference on Antennas and Propagation (EuCAP 2014), pp. 609-613, The Hague, Netherlands, April 2014.

[21] H. Liu, Y. Liu, W. Zhang, and S. Gao, "An ultra-wideband horizontally polarized omnidirectional circular connected Vivaldi antenna array," IEEE Transactions on Antennas and Propagation, vol. 65, no. 8, pp. 4351-4356, 2017.

[22] Computer Simulation Technology GmbH http://www.3ds. com/productsservices/simulia/products/cst-studio-suite.

[23] C. Craeye and D. Gonzalez-Ovejero, "A review on array mutual coupling analysis,” Radio Science, vol. 46, no. 2, p. 25 , 2011.

[24] K. Alkhalifeh, R. Sarkis, and C. Craeye, "Design of a Novel 3D Circular Vivaldi Antennas Array for Ultra-wideband NearField Radar Imaging," in Proceedings of the 6th European Conference on Antennas and Propagation (EuCAP), Prague, Czech Republic, March 2012.

[25] https://www.pasternack.com/images/ProductPDF/RG402-U. pdf. 